\title{
BMJ Open Validating prediction scales of type 2 diabetes mellitus in Spain: the SPREDIA-2 population-based prospective cohort study protocol
}

\author{
Miguel Ángel Salinero-Fort, ${ }^{1}$ Carmen de Burgos-Lunar, ${ }^{2}$ José Mostaza Prieto, ${ }^{3}$ \\ Carlos Lahoz Rallo, ${ }^{3}$ Juan Carlos Abánades-Herranz,, ${ }^{4}$ Paloma Gómez-Campelo, ${ }^{5}$ \\ Fernando Laguna Cuesta, ${ }^{3}$ Eva Estirado De Cabo, ${ }^{3}$ Francisca García Iglesias, ${ }^{3}$ \\ Teresa González Alegre, ${ }^{3}$ Belén Fernández Puntero, ${ }^{6}$ Luis Montesano Sánchez, ${ }^{6}$ \\ David Vicent López, ${ }^{6}$ Víctor Cornejo Del Río, ${ }^{6}$ Pedro J Fernández García, ${ }^{6}$ \\ Concesa Sabín Rodríguez, ${ }^{6}$ Silvia López López, ${ }^{6}$ Pedro Patrón Barandío, ${ }^{6}$ \\ the SPREDIA-2 Group
}

To cite: Salinero-Fort Miguel Á, de Burgos-Lunar C, Mostaza Prieto J, et al. Validating prediction scales of type 2 diabetes mellitus in Spain: the SPREDIA-2 population-based prospective cohort study protocol. BMJ Open 2015;5:e007195. doi:10.1136/bmjopen-2014007195

- Prepublication history for this paper is available online. To view these files please visit the journal online (http://dx.doi.org/10.1136/ bmjopen-2014-007195).

Received 21 November 2014 Revised 29 May 2015 Accepted 16 June 2015

\section{CrossMark}

For numbered affiliations see end of article.

Correspondence to Dr Miguel Ángel Salinero-Fort; miguel.salinero@salud. madrid.org

\section{ABSTRACT}

Introduction: The incidence of type 2 diabetes mellitus (T2DM) is increasing worldwide. When diagnosed, many patients already have organ damage or advance subclinical atherosclerosis. An early diagnosis could allow the implementation of lifestyle changes and treatment options aimed at delaying the progression of the disease and to avoid cardiovascular complications. Different scores for identifying undiagnosed diabetes have been reported, however, their performance in populations of southern Europe has not been sufficiently evaluated. The main objectives of our study are: to evaluate the screening performance and cut-off points of the main scores that identify the risk of undiagnosed T2DM and prediabetes in a Spanish population, and to develop and validate our own predictive models of undiagnosed T2DM (screening model), and future T2DM (prediction risk model) after 5-year follow-up. As a secondary objective, we will evaluate the atherosclerotic burden of the population with undiagnosed T2DM.

Methods and analysis: Population-based prospective cohort study with baseline screening, to evaluate the performance of the FINDRISC, DANISH, DESIR, ARIC and QDScore, against the gold standard tests: Fasting plasma glucose, oral glucose tolerance and/or HbA1c. The sample size will include 1352 participants between the ages of 45 and 74 years. Analysis: sensitivity, specificity, positive predictive value, negative predictive value, likelihood ratio positive, likelihood ratio negative and receiver operating characteristic curves and area under curve. Binary logistic regression for the first 700 individuals (derivation) and last 652 (validation) will be performed. All analyses will be calculated with their $95 \% \mathrm{Cl}$; statistical significance will be $p<0.05$.

Ethics and dissemination: The study protocol has been approved by the Research Ethics Committee of the Carlos III Hospital (Madrid). The score performance and predictive model will be presented in

\section{Strengths and limitations of this study}

- Our population-based study will have greater generalisability than those studies carried out with patients attending a clinical setting. However, there are some limitations that need to be mentioned. First, a certain amount of selection bias is inevitable; older people or those who are very ill will be less prone to participate in the study. In order to avoid an unrepresentative sample of patients, a multistage sample will be collected, ensuring the study participants are representative of the general population.

- Second, a classification bias is possible due to the use of an imperfect gold standard. The oral glucose tolerance test, fasting plasma glucose and glycated haemoglobin will be chosen in order to avoid this possibility.

- Third, a confounding bias constitutes a mistake most frequently made in this type of study. In predictive models (logistic multivariable model), confounding will be assumed to be present for variables accounting for at least a $10 \%$ change of the $\mathrm{OR}$. To avoid a confounding bias, the variables identified as confounding will remain in the model.

medical conferences, workshops, seminars and round table discussions. Furthermore, the predictive model will be published in a peer-reviewed medical journal to further increase the exposure of the scores.

\section{INTRODUCTION}

The incidence and prevalence of type 2 diabetes mellitus (T2DM) is increasing worldwide $^{12}$ and it is expected to continue growing 
during the next decades. T2DM is a major cause of morbidity, mortality, and increasing health costs in $\mathrm{USA}^{3} 4$ and in Europe. ${ }^{5}$ Usually, prediabetes (impaired fasting glucose or impaired glucose tolerance) will precede the diagnosis of T2DM. It is estimated that the absolute annual incidence rates of T2DM in individuals with prediabetes vary from $5 \%$ to $10 \%{ }^{6}$

When patients are initially diagnosed with T2DM, they frequently have organ damage ${ }^{7}$; between $20 \%$ and $40 \%$ of the patients already have retinopathy, ${ }^{8} 24.9 \%$ have microalbuminuria ${ }^{9}$ and $19 \%$ have subclinical atherosclerosis. ${ }^{10}$ This constitute a significant health problem considering the high proportion of patients with T2DM who remain asymptomatic, ${ }^{11}{ }^{12}$ and that undiagnosed T2DM has been associated with a higher risk of cardiovascular disease and mortality, ${ }^{13}$ the leading cause of death in these patients. ${ }^{14}$ An early diagnosis could allow the implementation of lifestyle changes and treatment options aimed at delaying the progression of the disease, and at avoiding cardiovascular complications. ${ }^{15}{ }^{16}$ For these reasons, early detection of undiagnosed T2DM is a public health priority. ${ }^{17}$

Early detection of T2DM can be performed measuring fasting plasma glucose (FPG) levels or with an oral glucose tolerance test (OGTT). However, the measurement of fasting or postchallenge glucose levels is an overly costly and time-consuming option to be offered to the whole population. Moreover, blood glucose levels are highly variable. For these reasons, simple scores for detecting people at risk of undiagnosed diabetes have been developed, ${ }^{18}$ generally with good sensitivities and specificities. Most scores come from USA or from countries in northern Europe ${ }^{19}$ However, Mediterranean countries have a different eating pattern and a different prevalence of risk factors. It has recently been demonstrated that olive oil consumption, the main cooking oil in Spain, Italy and Greece, protects from the development of diabetes. ${ }^{20}$ Therefore, the performance of these scores in populations from southern Europe should be evaluated.

The main objectives of our study will be to evaluate, in a Spanish population, the screening performance and cut-off points of the main scores that identify the risk of undiagnosed T2DM and prediabetes, and to develop and validate our own predictive model of undiagnosed T2DM (screening model), and future T2DM (prediction risk model) after 5 years of follow-up. As a secondary objective, we will evaluate the atherosclerotic burden of the population with undiagnosed and diagnosed T2DM.

\section{MATERIALS AND METHODS}

\section{Study design and participants}

The Screening PRE-diabetes and type 2 DIAbetes (SPREDIA-2) study is a population-based prospective cohort study with baseline screening in the region of Madrid (Spain). The study will be carried out from 1 January 2013 to 31 December 2018.
The target population will be a random sample of urban subjects living in the north-west metropolitan area of Madrid (Spain), and with healthcare coverage. Inclusion criteria will be: age between 45 and 75 years. In the reference population, there are approximately 183000 people of this age.

In our study, potential participants, out of the overall individuals with healthcare coverage from the Spanish National Health Service, will be randomly selected by their individual health cards accessed through an electronic health records database.

The study procedure will be divided into three phases (figure 1). First, the potential participants will be sent a letter, signed by their general practitioner, explaining the objectives of the study and inviting them to participate. Second, participants will be contacted by telephone, for solving doubts, and those interested in participating will be cited for the assessment. In order to minimise the loss attributable to failure in locating the patient, up to four telephone calls will be made at different times and on different days. Pregnant women, participants with severe chronic or terminal illnesses, institutionalised participants or those chronically treated with steroids or antipsychotic drugs, will be excluded from the study. Third, participants will be attended to at the assessment.

Those participants not interested in participating will be asked to voluntarily report their sex, age and diabetes status in order to be compared with the participating population.

\section{Procedure}

\section{Baseline screening}

Participants will be scheduled in the outpatient clinic of the Hospital Carlos III after an overnight fast. On arrival, and after signing a consent form, a fasting blood analysis will be obtained for measuring the blood levels for glucose, creatinine, glycated haemoglobin (HbAlc), lipids and lipoproteins. Samples of plasma and serum will be frozen at $-80^{\circ} \mathrm{C}$ for further analysis. Also, a whole blood sample will be obtained for DNA extraction and a urine specimen will be collected for determining microalbuminuria.

Immediately after blood sampling, all participants without a previous diagnosis of diabetes will have an OGTT with $75 \mathrm{~g}$ of anhydrous glucose in a total fluid volume of $300 \mathrm{~mL}$. A second blood sample will be obtained $2 \mathrm{~h}$ later.

During the time between the taking of blood samples, patients will complete a protocolised schedule, designed in advance, to collect all the variables of the study, as follows: diabetes risk scores for predicting diabetes and a set of questionnaires will be self-administrated, clinical variables and treatments will be collected by the doctors, and anthropometric parameters assessed by nurses.

\section{Follow-up}

After 5 years, the patients will be scheduled for a follow-up visit. Clinical outcomes (development of 


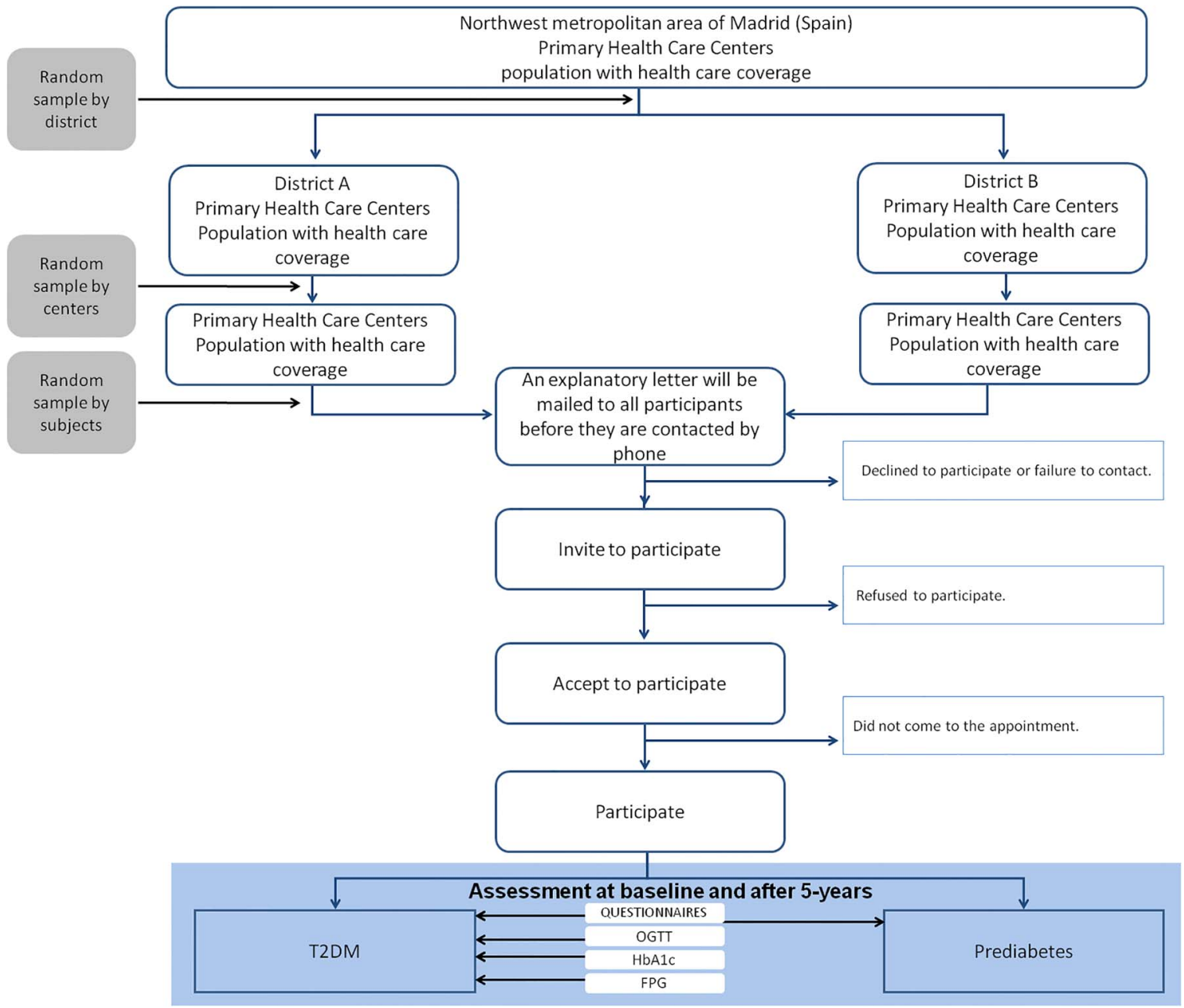

Figure 1 Study flow chart (FPG, fasting plasma glucose; HbA1c, glycated haemoglobin; OGTT, oral glucose tolerance test; T2DM, type 2 diabetes mellitus.

diabetes mellitus or initiation of antidiabetic agents) will be obtained from primary care electronic medical records. All participants will have a brief physical examination and a fasting blood analysis for determining glucose, creatinine, lipid parameters and HBAlc. Non-diabetic participants will have an OGTT. The vital status of patients lost to follow-up will be checked using the information provided by their general practitioners, family members and/or from a death certificate database available from the National Institute of Statistics.

\section{Variables}

The main outcome will be the diabetes status, and will be performed according to the American Diabetes Association (ADA) criteria, $^{21}$ as follows:

- Prediabetes will be defined as not having previous diabetes, but having HbAlc between $5.7 \%$ and $6.4 \%$, or FPG between 100 and $125 \mathrm{mg} / \mathrm{dL}$ (impaired fasting glucose), or a 2 h-OGTT plasma glucose between 140 and $199 \mathrm{mg} / \mathrm{dL}$ (impaired glucose tolerance).

- Undiagnosed diabetes will be defined as not having previous diabetes, but having $\mathrm{HbA} 1 \mathrm{c} \geq 6.5 \%$, or FPG $\geq 126 \mathrm{mg} / \mathrm{dL}, \quad$ or $2 \mathrm{~h}$ OGTT plasma glucose $\geq 200 \mathrm{mg} / \mathrm{dL}$.

- Finally, diagnosed diabetes will be defined as having previous diagnosis of diabetes.

Also, the following variables will be collected:

- Sociodemographic variables: date of birth, gender, nationality, ethnicity (White, Indian, Pakistani, Bangladeshi, other Asian, Black Caribbean, Black African, Chinese, other ethnic group) and educational level (no education completed, primary, secondary, university).

- Clinical variables and treatments: family history of prevalent diseases (diabetes, coronary heart disease, cerebrovascular disease), cardiovascular risk factors (smoking, hypertension, alcohol ingestion), comorbidities and current treatments. Also, hypertension will be considered if the patient has a blood pressure $>140 / 90 \mathrm{~mm} \mathrm{Hg}$ or is treated with antihypertensive drugs.

- Other clinical variables: Ankle-Brachial Index (ABI) will be determined using a portable bidirectional $8 \mathrm{MHz}$ echo-Doppler and a calibrated mercury sphygmomanometer. Systolic blood pressure (SBP) 
will be measured in the posterior tibial and dorsalis pedis artery of both lower limbs, and in the brachial artery of both upper limbs. The ABI value for each of the lower limbs will be determined by dividing the highest SBP obtained in each lower limb, whether posterior tibial or dorsalis pedis, by the highest SBP obtained in either of the upper limbs. Also, an eco-Doppler of both carotids will be performed with a 7.5 MHz probe (Sonosite Micromaxx Ultrasound, Sonosite Inc, Bothell, Washington, USA). Patients will lay in the supine position with the neck rotated to the side opposite that of the examination. One centimetre images will be obtained from the distal wall of the common carotid artery proximal to the bifurcation, in three different angles views. Intima-media thickness (IMT) will be obtained with automated software (Sonosite, Sonocalc IMT Software, Sonosite Inc, Bothell, Washington, USA), and the maximal region and the overall mean IMT values for each of the six segments analysed (3 angles in 2 territories), will be calculated. IMT values for the three different projections and for right and left carotid arteries will be averaged to obtain the maximumcommon carotid artery (CCA)-IMT and the mean-CCA-IMT. Carotid plaques will be defined as a local thickening of the intima $>1 \mathrm{~mm}$ or a thickening of $>50 \%$ of the surrounding IMT value. Carotid stenosis will be determined according to lumen narrowing and flow velocities.

- Anthropometric parameters: All participants will have a physical examination with the determination of height, weight and waist circumference (midway between lowest rib and the iliac crest). Blood pressure will be measured three times after the participant has been seated for $5 \mathrm{~min}$, and the result will be the mean of the last 2 measurements.

- Laboratory measurements: blood levels of glucose, creatinine, HbAlc, lipids and lipoproteins. Samples of plasma and serum will be frozen at $-80^{\circ} \mathrm{C}$ for further analysis. Also, a whole blood sample will be obtained for DNA extraction, and a urine specimen will be collected for determining microalbuminuria. Finally, glucose will be measured by the glucose oxidase method. Cholesterol and triglycerides will be determined by enzymatic assays. Low-density lipoprotein (LDL) cholesterol will be calculated according to the Friedewald formula (LDL cholesterol=total cholesterol (high-density lipoprotein (HDL) cholesterol +trigyceride/5)) in participants with triglycerides below $400 \mathrm{mg} / \mathrm{dL}$. HDL cholesterol will be measured after precipitation of apoB lipoproteins. HbAlc will be measured using a high-performance liquid chromatography method.

- Participants will complete a set of questionnaires during their visit, including the following: the 14-item questionnaire assessing adherence to the Mediterranean diet, ${ }^{22}$ a brief physical activity questionnaire (light, moderate, vigorous and sport level physical activity), the Patient Health Questionnaire-9, (PHQ-9), ${ }^{23}$ to assess depression, and the 12-item Short Form Health Survey $(\mathrm{SF}-12)^{24}$ to assess health-related quality of life; and for males, a five-item version of the international index of erectile function (IIEF-5) will be included. $^{25}$ Also, participants will complete the required questions for the validation of each diabetes risk scale.

- Diabetes risk scores for predicting diabetes. Participants will complete an extensive questionnaire to collect the data necessary to classify them according to the different diabetes risk scores for

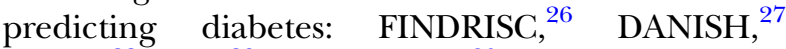
DESIR, ${ }^{28}$ ARIC $^{29}$ and QDScore ${ }^{30}$

$O$ The FINDRISC ${ }^{31}$ is an eight-item score $(0-26$ points) that collects data about age, sex, weight and height, waist circumference, use of concomitant medication (blood pressure), history of blood glucose disorders, physical activity and daily consumption of vegetables, fruits or berries. A higher score indicates a higher risk. The score was developed in Finland (2003). To date, external validation has been performed in 11 countries: Germany, ${ }^{32-34}$ the UK, ${ }^{18}$ Bulgaria, ${ }^{35}$ China, ${ }^{36}$ Kuwait, ${ }^{37}$ Taiwan, ${ }^{38}$ the Philippines, ${ }^{39}$ Italy, ${ }^{40}$ Spain, ${ }^{41}$ the $\mathrm{USA}^{42}$ and Greece ${ }^{43}$ (table 1). This score has also been used as a screening tool to predict the risk of incident diabetes in prospective studies (table 2).

$\bigcirc$ The DANISH ${ }^{27}$ score includes the following variables: age, sex, body mass index (BMI), known hypertension ("Have you ever been told that you have or have had hypertension?"), physical activity at leisure time (sedentary, moderate, active and competitive sport) and family history of diabetes. The study was conducted in Denmark (2004). To date, external validation has been performed in Australia, ${ }^{49}$ the $\mathrm{UK}^{18}$ and Taiwan. ${ }^{38}$

The $\operatorname{DESIR}^{28}$ score includes the following variables: sex, waist circumference, hypertension $(\geq 140 / 90 \mathrm{~mm} \mathrm{Hg})$ or hypertension treatment, family history of diabetes and smoking. The score was developed in France (2008).

$\bigcirc$ The ARIC $^{29}$ score includes the following variables: age, parental history of diabetes, ethnicity (Black), SBP, waist circumference and height. The score was elaborated in USA (2005).

O The QDScore $^{30}$ (http://www.qdscore.org/) includes the following variables: ethnicity (9 ethnicities: White, Indian, Pakistani, Bangladeshi, other Asian, Black Caribbean, Black African, Chinese, other ethnic group), age, BMI, smoking status (non smoker; ex-smoker; light smoker: <10; moderate smoker: 10-19; heavy smoker: $>19$ ), history of diabetes in a first degree relative, cardiovascular 
Table 1 Comparative data from cross-sectional studies that have used the FINDRISC score to evaluate the prevalence of undiagnosed T2DM

\begin{tabular}{|c|c|c|c|c|c|c|c|c|c|c|}
\hline Study & Country & Age & Sample & $\mathbf{N}$ & $\mathrm{Se}$ & Sp & NPV & Cut-off & AUC & Gold standard \\
\hline $\begin{array}{l}\text { Lindström and } \\
\text { Tuomilehto } 26\end{array}$ & Finland & $35-64$ & $\begin{array}{l}\text { Without antidiabetic } \\
\text { drug }\end{array}$ & 4746 & 77 & 66 & 99 & $\geq 9$ & 0.80 & OGTT and/or FPG* \\
\hline Franciosi et a ${ }^{40}$ & Italy & $55-75$ & $\begin{array}{l}\text { No CV events } \& \geq 1 \\
\text { CVRF }\end{array}$ & 1377 & 86 & 41 & 93 & $\geq 9$ & 0.72 & OGTT and/or FPG* \\
\hline Saaristo (2005) ${ }^{44}$ & Finland & $45-74$ & $\begin{array}{l}\text { Population random } \\
\text { sample }\end{array}$ & 2966 & $\begin{array}{l}66 \text { (men) } \\
70 \text { (women) }\end{array}$ & $\begin{array}{l}69 \text { (men) } \\
61 \text { (women) }\end{array}$ & $\begin{array}{l}94 \text { (men) } \\
96 \text { (women) }\end{array}$ & $\geq 11$ & $\begin{array}{l}0.72 \text { (men) } \\
0.73 \text { (women) }\end{array}$ & OGTT and/or FPG* \\
\hline Rathmann et $\left.a\right|^{\beta 2}$ & Germany & $55-74$ & $\begin{array}{l}\text { Population-based } \\
\text { study }\end{array}$ & 1353 & 82 & 43 & 96 & $\geq 9$ & 0.65 & OGTT and/or FPG* \\
\hline Bergmann et $a^{33} \dagger$ & Germany & $41-79$ & $3 \mathrm{DRF}$ & 526 & 70 & 63 & & $\geq 9$ & 0.75 & OGTT and/or FPG* \\
\hline Korhonen (2009) & Finland & $45-70$ & $\geq 1 \mathrm{DRF}$ & 1469 & 62 & 59 & & $\geq 12$ & & OGTT \\
\hline Li et $a{ }^{\beta 4}$ & Germany & $14-93$ & Family MS & 771 & 70.1 & 78.6 & 96 & $\geq 14$ & 0.81 & OGTT and/or FPG* \\
\hline Lin et $a \beta^{\beta 8}$ & Taiwan & $\geq 18$ & $\begin{array}{l}\text { Population-based } \\
\text { study }\end{array}$ & 2759 & 67 & 67 & & & 0.73 & $\mathrm{FPG}^{*}$ \\
\hline Witte et $a l^{18}$ & The UK & $35-55$ & Civil servants & 6990 & 40 & 82 & & $\geq 9$ & 0.67 & OGTT and/or FPG* \\
\hline Al Khalaf et $a l^{\beta 7}$ & Kuwait & $>19$ & Civil servants & 460 & 83 & 70 & & $\geq 9$ & & FPGף \\
\hline Makrilakis et $a f^{43}$ & Greece & $35-75$ & High-risk individuals & 869 & 81 & 60 & 96 & $\geq 15$ & 0.72 & OGTT and/or FPG* \\
\hline Tankova et a/ ${ }^{\beta 5}$ & Bulgaria & $22-78$ & $\geq 1 \mathrm{DRF}$ & 2169 & 78 & 62 & & $\geq 12$ & 0.71 & OGTT and/or FPG $\ddagger$ \\
\hline Soriguer et $a{ }^{41}$ & Spain & $>30$ & $\begin{array}{l}\text { Population-based } \\
\text { study }\end{array}$ & 1051 & & & & $\geq 9$ & 0.74 & OGTT and/or FPG* \\
\hline $\mathrm{Ku}$ and KegelsI ${ }^{39}$ & $\begin{array}{l}\text { The } \\
\text { Philippines }\end{array}$ & 20-92 & $\begin{array}{l}\text { Population-based } \\
\text { study }\end{array}$ & 1752 & 62 & 74 & 96 & $\geq 9$ & 0.74 & $\begin{array}{l}\text { FPG/FPG or } \\
\mathrm{OGTT}^{\star *}\end{array}$ \\
\hline Costa $(2013)^{46}$ & Spain & $45-75$ & $\begin{array}{l}\text { Population random } \\
\text { sample }\end{array}$ & 1712 & 76 & 52 & 95 & $\geq 14$ & $\begin{array}{l}0.67 \text { (men) } \\
0.76 \text { (women) }\end{array}$ & OGTT \\
\hline Zhang et $a l^{42}$ & USA & $\geq 20$ & $\begin{array}{l}\text { Population-based } \\
\text { study }\end{array}$ & 20633 & $\begin{array}{l}75 \text { (men) } \\
72 \text { (women) }\end{array}$ & $\begin{array}{l}63 \text { (men) } \\
69 \text { (women) }\end{array}$ & $\begin{array}{l}98 \text { (men) } \\
99 \text { (women) }\end{array}$ & $\begin{array}{l}10 \text { (men) } \\
12 \text { (women) }\end{array}$ & 0.75 & $\begin{array}{l}\text { FPG, OGTT and/or } \\
\mathrm{HbA} 1 \mathrm{c}\end{array}$ \\
\hline
\end{tabular}

*WHO. Definition and diagnosis of diabetes mellitus and intermediate hyperglycaemia. 1999

tGerman version of FINDRISC (6 variables).

$¥ W H O$. Definition and diagnosis of diabetes mellitus and intermediate hyperglycaemia. 2006.

TADA. Report of the Expert Committee on the diagnosis and classification of diabetes mellitus. 2003.

${ }^{* *}$ First step: FPG or casual blood glucose; second step: If FPG $\geq 126 \mathrm{mg} / \mathrm{dL}$ or casual blood glucose $\geq 200 \mathrm{mg} / \mathrm{dL}$, the diagnosis was confirmed with new FPG ( $\geq 126 \mathrm{mg} / \mathrm{dL}$ ) or OGTT ( $\geq 200 \mathrm{mg} / \mathrm{dL}$ ).

ADA, American Diabetes Association; AUC, area under curve; CV, cardiovascular; CVRF, CV risk factors; DRF, diabetic risk factors; FPG, fasting plasma glucose; HbA1c, glycated haemoglobin;

MS, metabolic syndrome; NPV, negative predictive value; OGTT, oral glucose tolerance test; Se, sensitivity; Sp, specificity; T2DM, type 2 diabetes mellitus. 


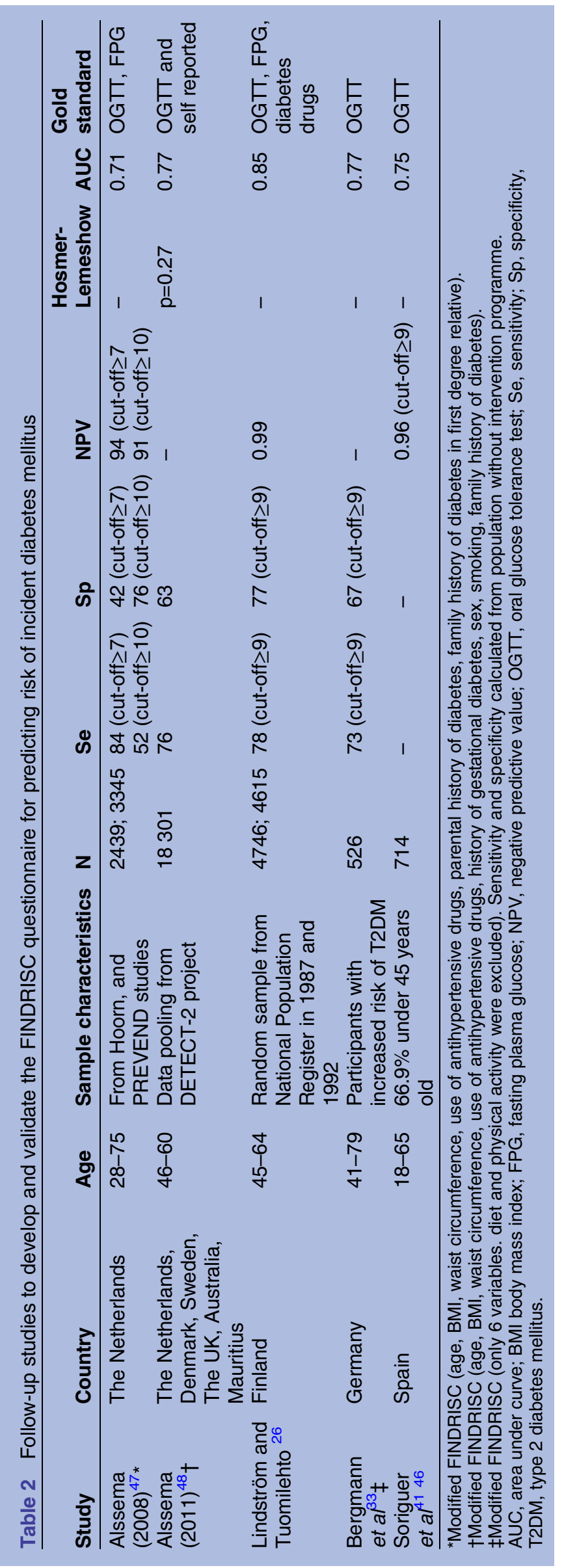

disease (heart attack, angina, stroke or transient ischaemic attack), treated hypertension and treatment with steroids. The study was conducted in the UK (2009). To date, external validation has been performed in the $\mathrm{UK}^{50}$

\section{Sample size}

For the main objective, the following assumptions have been accepted: an $\alpha$ error of 0.05 , a precision rate of $9 \%$ in a bilateral contrast, for an estimated sensitivity rate of $81 \%^{26}$ and an estimated prevalence of undiagnosed DM of $6 \%^{51}$; the overall sample size required 1217 participants. Given these assumptions, and expecting that $10 \%$ of individuals do not meet the inclusion criteria, the final sample size will require 1352 participants.

\section{Data analysis plan}

Descriptive statistical analysis of each variable will be carried out, summarising the quantitative variables (mean and SD, or median and the IQR for asymmetric distributions) and the qualitative variables (relative frequency). Participants not willing to participate in the study will be compared with participants, according to sex, age and known diabetes status.

For the first main objective, a $2 \times 2$ contingence table with T2DM (Yes/No) according to OGTT, FPG or HbAlc (Yes/No) and a FINDRISC score with a cut-off point of 8 $(<8)$, will be created. This same process will be repeated for cut-off points from 9 to 16 . Sensitivity, specificity, positive and negative predictive values, and positive and negative likelihood ratios will be calculated for each table. Subsequently, the process will be repeated with the rest of the predictive risk scale scores: ARIC, QDScore, DANISH, DESIR. Finally, $2 \times 2$ contingency tables will be produced for each scale with the variable prediabetes (Yes/No).

The most appropriate cut-off point on the receiver operating characteristic (ROC) curve will be calculated in order to combine the best sensitivity with the least amount of false positives (1-specificity). When comparing scores, the score with a better areas under curve (AUC) is preferred due to its better diagnostic power. The Hanley and McNeil test to contrast hypotheses will be used. Finally, we will develop and validate an own predictive model using a binary logistic regression analysis with the backward stepwise method, with the dependent variable being the presence or not of undiagnosed DM (Yes/No). Following this, independent variables with a significance of $<0.20$ in the univariate analysis will be introduced into the model. A split-sample technique will be used to test a prediction rule; so, $50 \%$ of the sample will be used for the development of the model, and the other $50 \%$ will be used for the validation. Regression coefficients from the predictive model will be transformed into a score by rounding up their value to the nearest whole number and multiplying by 10 . 
These scores will enable different cut-off points within the predictive model to be established. For each of these, the sensitivity, specificity, and positive and negative predictive values will be calculated. Finally, the best cut-off point on a ROC curve will be estimated. To calibrate the model, the Hosmer-Lemeshow test will be used and applied to the same working sample (internal validity), and the validation sample (generalisability). The ROC AUC measures discrimination, and the ability of the test to classify those with and without T2DM. Thus, for all the possible pairs of individuals (formed by an individual who had an event and an individual who did not), the model can predict the proportion of those who have a higher probability of having the event (in this case T2DM). An acceptable discrimination area for the model will be from 0.7 .

The same methodology will be applied to develop and validate the 5 years prediction risk model of future T2DM.

All analyses will be calculated with their 95\% CI; statistical significance will be set at $\mathrm{p}<0.05$. Statistical processing of the data will be performed with SPSS (SPSS for windows, V.19.0; IBM Corp, Armonk, New York, USA).

\section{Ethics and dissemination}

The study protocol has been approved by the Research Ethics Committee of the Hospital Carlos III in Madrid. The study will comply with the International Guidelines for Ethical Review of Epidemiological Studies (Geneva, 1991). All patients will sign an informed consent form.

Finally, to guarantee the quality of reporting of the study, the protocol has been developed according to the STARD (Standards for Reporting of Diagnostic Accuracy) statement. ${ }^{52}$

The score performance and predictive model will be presented in medical conferences, workshops, seminars and round table discussions, and free copies for download will be made available on the website of the primary care administration (https://saluda.salud. madrid.org/ATENCIONPRIMARIA/Paginas/Default.aspx). Furthermore, the predictive model will be published in a peer-reviewed medical journal to further increase the exposure of the scores.

\section{DISCUSSION}

Diabetes is increasingly been diagnosed in industrialised countries, mainly as a consequence of the epidemic of obesity. Patients with diabetes have high morbidity and mortality, and are responsible for overconsumption of resources. Cardiovascular disease is the leading cause of death in this population.

Early diagnosis of diabetes, before the onset of clinical symptoms, would favour the implementation of lifestyle modifications that could retard its progression and avoid the development of atherosclerotic lesions. Moreover, the demonstration that participants with diabetes have a higher atherosclerosis burden at the time of diagnosis, will further strength the recommendation of establishing strategies directed to early detection and treatment.

Different screening strategies have been adopted in order to detect undiagnosed T2DM. Currently, there are two basic methods, a population based and an opportunistic, or high risk, strategy.

Regarding the population based screening strategy, there are at least three possible approaches: (1) to determine blood fasting glucose-a strategy that serves to establish the existence of prediabetes or undiagnosed T2DM; (b) to estimate the long-term risk of T2DM-a strategy that ignores the actual blood sugar level and is based on predictive models and (c) to apply scores as screening tools, in order to identify high-risk populations that could benefit from a targeted screening programme, either measuring fasting or postprandial glucose levels.

The use of FPG levels as a population-level screening tool is not recommended due to the variability of its plasma levels and its low cost-effectiveness. ${ }^{53}$ However, the cost-effectiveness improves when used in high-risk subgroups (ie, age over 45 years, history of gestational diabetes, family history of diabetes, obesity, hypertension or dyslipidaemia). Currently, there is no consensus on the selection of the optimal high-risk subgroups or on how regularly these screens should be performed. As a consequence, risk scores have been developed in order to better identify high risk participants.

The most well-known scores are those developed by the $\mathrm{ADA},{ }^{54}$ the University of Maryland (http:// www.healthcalculators.org/calculators/diabetes.asp), the German Institute of Human Nutrition ${ }^{55}$ and the Finnish Diabetes Association (Finnish diabetes risk score, FINDRISC).${ }^{26}$ They all have certain common advantages: the variables are simple to collect; they have open access via websites; they are inexpensive and quick, and can be self-administered. All have a similar diagnostic accuracy, with equivalent AUC for ROC, compared with those that add laboratory variables. ${ }^{29}{ }^{56}$ Despite their widespread use, few studies have directly compared the performance of the different scores. Lin et al, ${ }^{38}$ in a cross-sectional study of 2759 Taiwanese participants, evaluated the performance of different T2DM risk scores for detecting T2DM, metabolic syndrome and chronic kidney disease. Their data showed the superiority of the FINDRISC and Cambridge scores for identifying the 'risk of undiagnosed or unknown DM' compared with the ARIC, QDScore, Oman, Danish, Thai, Asian Indian, Dutch and DESIR scores.

Despite their well-known performance in some countries, there is a lack of either validated or autochthonous scores in countries of southern Europe. The development of local scores is relevant due to the different prevalence of diabetic risk factors among countries. Moreover, some alimentary habits influencing the risk of diabetes risk drastically differ among different regions. To date, in Spain, no standard score to predict the 'risk of undiagnosed T2DM' has been sufficiently evaluated. Soriguer et $a l,{ }^{41}$ in Málaga (Spain), evaluated the performance of the FINDRISC score in a sample of young individuals 
(60\% under 45 years), and Cabrera de León et al, ${ }^{57}$ in Canary Islands (Spain), developed and validated a clinical prediction diabetes risk score. Both scores have external validation limitations mainly related to the lower prevalence of T2DM in younger adults,${ }^{58}$ and the high prevalence of obesity and T2DM in Canary Islands. ${ }^{59}$

In light of the above, it is pertinent to explore how valid the main T2DM risk scores (FINDRISC, ARIC, QDScore, DANISH, DESIR) are when applied to Spain. We will determine the most appropriate score to be used in a Spanish primary healthcare setting by exploring the diagnostic efficiency of the scores, the optimum cut-off point for the population studied, and the diagnostic accuracy of the scores for T2DM and metabolic syndrome. The data provided by the study will also contribute to the development of a predictive model that would serve as a valuable tool for identifying participants with a high risk of 'undiagnosed T2DM', candidates for further screening strategies to confirm the diagnosis (ie, laboratory tests: FPG, OGTT or HbA1C). This sequential approximation (step 1: prediction score and step 2: laboratory testing) will enable a more efficient use of resources, and the possibility of calculating the diabetes risk without accessing health services.

With regard to predicting risk of developing T2DM, a recent external validation study ${ }^{60}$ considered 12 prediction scores as basic because they were grounded on variables that can be assessed non-invasively. FINDRISC, DESIR and QDScore were included, and the external validation showed that these scores performed well to identify those at high risk of future diabetes. However, the scores should probably be adapted to the local setting and corrected for the incidence of T2DM of the population in which they are to be applied.

Also, an accurate model for predicting incident T2DM in the Spanish population will identify a population subgroup that could benefit from therapeutic interventions and lifestyle modification.

Finally, several mechanisms have been suggested ${ }^{61}$ to explain why diabetes risk scores could help to improve patient outcomes. For example, clinicians could easily identify high risk patients in the clinical setting and could offer advice related to changes in patient behaviour and lifestyle. Also, people could easily assess their own risk, which might prompt them to clinical consultation.

\footnotetext{
Author affiliations

${ }^{1}$ Gerencia Adjunta de Planificación y Calidad, Atención Primaria. Servicio Madrileño de Salud, Instituto de Investigación Sanitaria del Hospital Universitario La Paz-IdiPAZ. Red de Investigación en servicios de salud en enfermedades crónicas (REDISSEC), Madrid, Spain

${ }^{2}$ Servicio de Medicina Preventiva, Hospital Universitario La Paz, Instituto de Investigación Sanitaria del Hospital Universitario La Paz-IdiPAZ. Red de Investigación en servicios de salud en enfermedades crónicas (REDISSEC), Madrid, Spain

${ }^{3}$ Servicio de Medicina Interna, Hospital Carlos III, Madrid, Spain

${ }^{4}$ Dirección Técnica de Docencia e Investigación. Gerencia Adjunta de Planificación y Calidad. Atención Primaria, Servicio Madrileño de Salud. Instituto de Investigación Sanitaria del Hospital Universitario La Paz-IdiPaz, Madrid, Spain
}

${ }^{5}$ Plataforma de apoyo al Investigador Novel. Instituto de Investigación Sanitaria del Hospital Universitario La Paz-IdiPAZ, Madrid, Spain ${ }^{6}$ Hospital Carlos III, Madrid, Spain

Acknowledgements The authors would like to thank the SPREDIA-2 Group, who will collaborate in the study.

Collaborators SPREDIA-2 Group: Leopoldo Pérez-Isla (Hospital Clínico de San Carlos), Vanessa Sánchez-Arroyo (Hospital Carlos III), Ignacio Vicente (Cs Monóvar), Sara Artola (Cs $\mathrm{M}^{\mathrm{a}}$ Jesús Hereza), $\mathrm{M}^{\mathrm{a}}$ Isabel Granados-Menéndez (Cs Monóvar), Domingo Beamud-Victoria (Cs Felipe II), Isidoro Dujovne-Kohan (Cs Los Castillos), Rosa María Chico-Moraleja (Hospital Central de la Defensa), Carmen Martín-Madrazo (Cs Monóvar), Juan Cárdenas-Valladolid (Gerencia de Atención Primaria), Concepción Aguilera Linde (Cs Ciudad Periodistas), Álvaro R Aguirre De Carcer Escolano (Cs La Ventilla), Patricio Alonso Sacristán (Cs Ciudad Periodistas), M Jesús Álvarez Otero (Cs Dr Castroviejo), Paloma Arribas Pérez (Cs Santa Hortensia), Maria Luisa Asensio Ruiz (Cs Fuentelarreina), Pablo Astorga Díaz (Cs Barrio Pilar), Begoña Berriatua Ena (Cs Dr Castroviejo), Ana Isabel Bezos Varela (Cs José Marva), María José Calatrava Triguero (Cs Ciudad Jardín), Carlos Casanova García (Cs Barrio Pilar), Ángeles Conde Llorente (Cs Barrio Pilar), Concepción Díaz Laso (Cs Fuentelarreina), Emilia Elviro García (Cs Ciudad Periodistas), Orlando Enríquez Dueñas (Cs Fuentelarreina), María Isabel Ferrer Zapata (Cs El Greco), Froilán Antuña (Cs Ciudad Periodistas), Maria Isabel García Lazaro (Cs Ciudad Periodistas), Maria Teresa Gómez Rodríguez (Cs Barrio Pilar), África Gómez Lucena (Cs La Ventilla), Francisco Herrero Hernández (Cs La Ventilla), Rosa Julián Viñals (Cs Dr Castroviejo), Gerardo López Ruiz Ogarrio (Cs Barrio Pilar), Maria Del Carmen Lumbreras Manzano (Cs José Marva), Sonsoles Paloma Luquero López (Cs Ciudad Periodistas), Ana Martínez Cabrera Peláez (Cs Barrio Pilar), Montserrat Nieto Candenas (Cs La Ventilla), María Alejandra Rabanal Carrera (Cs Barrio Pilar), Ángel Castellanos Rodríguez (Cs Ciudad Periodistas), Ana López Castellanos (Cs La Ventilla), Milagros Velázquez García (Cs Barrio Pilar) and Margarita Ruiz Pacheco (Cs Dr Castroviejo)

Contributors MAS-F had the original idea for the study and prepared the first draft of the manuscript and coordinated responses from the authors. MAS-F, JCA-H, JMP, CLR and CdB-L are steering committee members of the SPREDIA-2 study. CdB-L developed the data collection databases. MAS-F and CdB-L contributed to the study design and analysis methods. PG-C provided major input into the study design and the analytical methods, and conducted the literature search using keyword database searches to identify relevant articles. JCA-H contributed to study selection, data extraction and methodological quality assessment. PG-C, MAS-F and DVL reviewed the articles. BFP and LMS contributed to writing the laboratory methods, and checked the accuracy and precision of the laboratory equipment. FLC, EEDC, FGI and TGA designed the case report form and the investigator's brochure. VCDR, PJFG, CSR, SLL and PPB were trained in Ankle Brachial Index measurement. All the authors reviewed and provided comments for the draft manuscripts, and read and gave approval for release of the final manuscript.

Funding This work was funded by the Agencia Laín Entralgo (Consejería de Sanidad de la Comunidad de Madrid) Grant 'RS_AP10/6'. It was co-funded by an unrestricted grant from Novo Nordisk (EPA-OD-HCIII). The funders had no role in study design, data collection and analysis, decision to publish, or preparation of the manuscript.

Competing interests None declared.

Patient consent Obtained.

Ethics approval Research Ethics Committee of the Hospital Carlos III in Madrid.

Provenance and peer review Not commissioned; externally peer reviewed.

Open Access This is an Open Access article distributed in accordance with the Creative Commons Attribution Non Commercial (CC BY-NC 4.0) license, which permits others to distribute, remix, adapt, build upon this work noncommercially, and license their derivative works on different terms, provided the original work is properly cited and the use is non-commercial. See: http:// creativecommons.org/licenses/by-nc/4.0/ 


\section{REFERENCES}

1. Ginter E, Simko V. Type 2 diabetes mellitus, pandemic in 21 st century. Adv Exp Med Biol 2012;771:42-50.

2. Wild S, Roglic G, Green A, et al. Global prevalence of diabetes: estimates for the year 2000 and projections for 2030. Diabetes Care 2004;27:1047-53.

3. Narayan KM, Gregg EW, Fagot-Campagna A, et al. Diabetes-a common, growing, serious, costly, and potentially preventable public health problem. Diabetes Res Clin Pract 2000;50(Suppl 2):S77-84.

4. Yusuf S, Hawken S, Ounpuu S, et al. Effect of potentially modifiable risk factors associated with myocardial infarction in 52 countries (the INTERHEART study): case-control study. Lancet 2004;364:937-52.

5. Ballesta García MJ, Carral San Laureano F, Olveira Fuster G, et al. [Economic costs associated to type 1 diabetes]. Rev Clínica Esp 2005;205:523-7.

6. Gerstein HC, Santaguida P, Raina $P$, et al. Annual incidence and relative risk of diabetes in people with various categories of dysglycemia: a systematic overview and meta-analysis of prospective studies. Diabetes Res Clin Pract 2007;78:305-12.

7. [No authors listed]. UK Prospective Diabetes Study 6. Complications in newly diagnosed type 2 diabetic patients and their association with different clinical and biochemical risk factors. Diabetes Res 1990;13:1-11.

8. Kohner EM, Aldington SJ, Stratton IM, et al. United Kingdom Prospective Diabetes Study, 30: diabetic retinopathy at diagnosis of non-insulin-dependent diabetes mellitus and associated risk factors. Arch Ophthalmol 1998;116:297-303.

9. Koopman RJ, Mainous AG, Liszka HA, et al. Evidence of nephropathy and peripheral neuropathy in US adults with undiagnosed diabetes. Ann Fam Med 2006;4:427-32.

10. Son JW, Jang EH, Kim MK, et al. Diabetic retinopathy is associated with subclinical atherosclerosis in newly diagnosed type 2 diabetes mellitus. Diabetes Res Clin Pract 2011;91:253-9.

11. Baan CA, Ruige JB, Stolk RP, et al. Performance of a predictive model to identify undiagnosed diabetes in a health care setting. Diabetes Care 1999;22:213-19.

12. Rathmann W, Haastert B, Icks A, et al. High prevalence of undiagnosed diabetes mellitus in Southern Germany: target populations for efficient screening. The KORA survey 2000 Diabetologia 2003;46:182-9.

13. DECODE Study Group, the European Diabetes Epidemiology Group. Glucose tolerance and cardiovascular mortality: comparison of fasting and 2-hour diagnostic criteria. Arch Intern Med 2001;161:397-405.

14. Bodegard J, Sundström J, Svennblad B, et al. Changes in body mass index following newly diagnosed type 2 diabetes and risk of cardiovascular mortality: a cohort study of 8486 primary-care patients. Diabetes Metab 2013;39:306-13.

15. Black JA, Sharp SJ, Wareham NJ, et al. Change in cardiovascular risk factors following early diagnosis of type 2 diabetes: a cohort analysis of a cluster-randomised trial. Br J Gen Pract 2014;64:e208-16.

16. Griffin SJ, Borch-Johnsen K, Davies MJ, et al. Effect of early intensive multifactorial therapy on 5-year cardiovascular outcomes in individuals with type 2 diabetes detected by screening (ADDITION-Europe): a cluster-randomised trial. Lancet 2011;378:156-67.

17. Harris MI, Klein R, Welborn TA, et al. Onset of NIDDM occurs at least 4-7 yr before clinical diagnosis. Diabetes Care 1992;15:815-19.

18. Witte DR, Shipley MJ, Marmot MG, et al. Performance of existing risk scores in screening for undiagnosed diabetes: an external validation study. Diabet Med 2010;27:46-53.

19. Brown N, Critchley J, Bogowicz P, et al. Risk scores based on self-reported or available clinical data to detect undiagnosed type 2 diabetes: a systematic review. Diabetes Res Clin Pract 2012;98:369-85.

20. Salas-Salvadó J, Bulló M, Babio N, et al. Reduction in the incidence of type 2 diabetes with the Mediterranean diet: results of the PREDIMED-Reus nutrition intervention randomized trial. Diabetes Care 2011;34:14-19.

21. American Diabetes Association. Standards of medical care in diabetes-2014. Diabetes Care 2014;37(Suppl 1):S14-80.

22. Martínez-González MA, García-Arellano A, Toledo E, et al. A 14-item Mediterranean diet assessment tool and obesity indexes among high-risk subjects: the PREDIMED trial. PLOS ONE 2012;7: e43134.

23. Spitzer RL, Kroenke K, Williams JB. Validation and utility of a self-report version of PRIME-MD: the PHQ primary care study. Primary care evaluation of mental disorders. Patient Health Questionnaire. JAMA 1999;282:1737-44

24. Ware J, Kosinski M, Keller SD. A 12-Item Short-Form Health Survey: construction of scales and preliminary tests of reliability and validity. Med Care 1996;34:220-33.
25. Rosen RC, Cappelleri JC, Smith MD, et al. Development and evaluation of an abridged, 5-item version of the International Index of Erectile Function (IIEF-5) as a diagnostic tool for erectile dysfunction. Int J Impot Res 1999;11:319-26.

26. Lindström J, Tuomilehto J. The diabetes risk score: a practical tool to predict type 2 diabetes risk. Diabetes Care 2003;26:725-31.

27. Glümer C, Carstensen B, Sandbaek A, et al. A Danish diabetes risk score for targeted screening: the Inter99 study. Diabetes Care 2004;27:727-33.

28. Balkau B, Lange C, Fezeu L, et al. Predicting diabetes: clinical, biological, and genetic approaches: data from the Epidemiological Study on the Insulin Resistance Syndrome (DESIR). Diabetes Care 2008;31:2056-61.

29. Schmidt MI, Duncan BB, Bang $\mathrm{H}$, et al. Identifying individuals at high risk for diabetes: the Atherosclerosis Risk in Communities study. Diabetes Care 2005;28:2013-18.

30. Hippisley-Cox J, Coupland C, Robson J, et al. Predicting risk of type 2 diabetes in England and Wales: prospective derivation and validation of QDScore. BMJ 2009;338:b880.

31. Salinero-Fort MA, Carrillo-de Santa Pau E, Abánades-Herranz JC et al, en nombre del Grupo MADIABETES. [Baseline risk of Diabetes Mellitus in Primary Health Care Services by FINDRISC test, associated factors and clinical outcome after 18 months of follow-up]. Rev Clínica Esp 2010;210:448-53

32. Rathmann W, Martin S, Haastert B, et al. Performance of screening questionnaires and risk scores for undiagnosed diabetes: the KORA Survey 2000. Arch Intern Med 2005;165:436-41.

33. Bergmann A, Li J, Wang L, et al. A simplified Finnish diabetes risk score to predict type 2 diabetes risk and disease evolution in a German population. Horm Metab Res 2007;39:677-82.

34. Li J, Bergmann A, Reimann M, et al. A more simplified Finnish diabetes risk score for opportunistic screening of undiagnosed type 2 diabetes in a German population with a family history of the metabolic syndrome. Horm Metab Res 2009;41:98-103.

35. Tankova T, Chakarova N, Atanassova I, et al. Evaluation of the Finnish Diabetes Risk Score as a screening tool for impaired fasting glucose, impaired glucose tolerance and undetected diabetes. Diabetes Res Clin Pract 2011;92:46-52.

36. Gao WG, Dong YH, Pang ZC, et al. A simple Chinese risk score for undiagnosed diabetes. Diabet Med 2010;27:274-81.

37. Al Khalaf MM, Eid MM, Najjar HA, et al. Screening for diabetes in Kuwait and evaluation of risk scores. East Mediterr Health $J$ 2010;16:725-31.

38. Lin JW, Chang YC, Li HY, et al. Cross-sectional validation of diabetes risk scores for predicting diabetes, metabolic syndrome, and chronic kidney disease in Taiwanese. Diabetes Care 2009;32 2294-6.

39. Ku GMV, Kegels G. The performance of the Finnish Diabetes Risk Score, a modified Finnish Diabetes Risk Score and a simplified Finnish Diabetes Risk Score in community-based cross-sectional screening of undiagnosed type 2 diabetes in the Philippines. Prim Care Diabetes 2013;7:249-59.

40. Franciosi M, De Berardis G, Rossi MCE, et al. Use of the diabetes risk score for opportunistic screening of undiagnosed diabetes and impaired glucose tolerance: the IGLOO (Impaired Glucose Tolerance and Long-Term Outcomes Observational) study. Diabetes Care 2005;28:1187-94

41. Soriguer F, Valdés S, Tapia MJ, et al. [Validation of the FINDRISC (FINnish Diabetes RIsk SCore) for prediction of the risk of type 2 diabetes in a population of southern Spain. Pizarra Study]. Med Clin (Barc) 2012;138:371-6.

42. Zhang L, Zhang Z, Zhang Y, et al. Evaluation of Finnish Diabetes Risk Score in screening undiagnosed diabetes and prediabetes among U.S. adults by gender and race: NHANES 1999-2010. PLoS ONE 2014;9:e97865.

43. Makrilakis K, Liatis S, Grammatikou S, et al. Validation of the Finnish diabetes risk score (FINDRISC) questionnaire for screening for undiagnosed type 2 diabetes, dysglycaemia and the metabolic syndrome in Greece. Diabetes Metab 2011;37:144-51.

44. Saaristo T, Peltonen M, Lindström J, et al. Cross-sectional evaluation of the Finnish Diabetes Risk Score: a tool to identify undetected type 2 diabetes, abnormal glucose tolerance and metabolic syndrome. Diab Vasc Dis Res 2005;2:67-72.

45. Korhonen PE, Jaatinen PT, Aarnio PT, et al. Waist circumference home measurement-a device to find out patients in cardiovascular risk. Eur J Public Health 2009;19:95-9.

46. Costa B, Barrio F, Piñol JL, et al. Shifting from glucose diagnosis to the new $\mathrm{HbA1c}$ diagnosis reduces the capability of the Finnish Diabetes Risk Score (FINDRISC) to screen for glucose abnormalities within a real-life primary healthcare preventive strategy. BMC Med 2013;21:11-45. 
47. Alssema M, Feskens EJ, Bakker SJ, et al. [Finnish questionnaire reasonably good predictor of the incidence of diabetes in The Netherlands]. Ned Tijdschr Geneeskd 2008;152: 2418-24.

48. Alssema M, Vistisen D, Heymans MW, et al. The Evaluation of Screening and Early Detection Strategies for Type 2 Diabetes and Impaired Glucose Tolerance (DETECT-2) update of the Finnish diabetes risk score for prediction of incident type 2 diabetes. Diabetologia 2011;54:1004-12.

49. Glümer C, Borch-Johnsen K, Colagiuri S. Can a screening programme for diabetes be applied to another population? Diabet Med 2005;22:1234-8.

50. Collins GS, Altman DG. External validation of QDSCORE(囚) for predicting the 10-year risk of developing type 2 diabetes. Diabet Med 2011;28:599-607.

51. Soriguer F, Goday A, Bosch-Comas A, et al. Prevalence of diabetes mellitus and impaired glucose regulation in Spain: the Di@bet.es Study. Diabetologia 2012;55:88-93.

52. Bossuyt PM, Reitsma JB, Bruns DE, et al. The STARD statement for reporting studies of diagnostic accuracy: explanation and elaboration. Ann Intern Med 2003;138:W1-12.

53. Waugh N, Scotland G, McNamee P, et al. Screening for type 2 diabetes: literature review and economic modelling. Health Technol Assess 2007;11:iii-iv, ix-xi, 1-125.
54. Bang H, Edwards AM, Bomback AS, et al. Development and validation of a patient self-assessment score for diabetes risk. Ann Intern Med 2009;151:775-83.

55. Schulze MB, Hoffmann $\mathrm{K}$, Boeing $\mathrm{H}$, et al. An accurate risk score based on anthropometric, dietary, and lifestyle factors to predict the development of type 2 diabetes. Diabetes Care 2007;30:510-15.

56. Aekplakorn W, Bunnag P, Woodward M, et al. A risk score for predicting incident diabetes in the Thai population. Diabetes Care 2006;29:1872-7.

57. Cabrera de León A, Coello SD, Rodríguez Pérez MDC, et al A simple clinical score for type 2 diabetes mellitus screening in the Canary Islands. Diabetes Res Clin Pract 2008;80:128-33.

58. Fagot-Campagna A, Saaddine JB, Flegal KM, et al. Diabetes, impaired fasting glucose, and elevated $\mathrm{HbA} 1 \mathrm{c}$ in U.S. Adolescents: the Third National Health and Nutrition Examination Survey. Diabetes Care 2001;24:834-7.

59. Cabrera de León A, Rodríguez-Pérez Mdel C, del Castillo-Rodríguez $\mathrm{JC}$, et al. [Coronary risk in the population of the Canary Islands, Spain, using the Framingham function]. Med Clin (Barc) 2006;126:521-6.

60. Abbasi A, Peelen LM, Corpeleijn E, et al. Prediction models for risk of developing type 2 diabetes: systematic literature search and independent external validation study. BMJ 2012;345:e5900.

61. Noble D, Mathur R, Dent T, et al. Risk models and scores for type 2 diabetes: systematic review. BMJ 2011;343:d7163. 